\title{
1. Behavioral and cognitive geography: introduction and overview
}

Daniel R. Montello

\subsection{INTRODUCTION: WHAT IS BEHAVIORAL AND COGNITIVE GEOGRAPHY?}

A tenet of everyday lay reasoning is that people do what they do because of what they believe - about themselves, about other people, about opportunities and threats in the surrounding world. About precedents in the past and consequences in the future. Researchers have dubbed such lay explanations for what people do as "commonsense," "intuitive," or "naive" reasoning (Egenhofer and Mark 1995; Hobbs and Moore 1985; Malle 2004; Ross 1977). The claim that people act in response to their beliefs has also attracted its share of serious scientific investigation, especially since the mid-20 $0^{\text {th }}$ century. Geographers and other scholars of human activity in natural and built environments joined these investigations during this time (see Chapter 2). Within the academic discipline of geography, such an explanation for human behavior came to be dubbed the "behavioral" approach. More recently, it is often referred to as "cognitive" geography; we explain below that these terms are not strictly synonymous. Briefly, behavioral and cognitive geography is an approach, or collection of approaches, to the study of human mental and physical activity in and concerning space, place, and environment. This Handbook presents a comprehensive and up-to-date overview of concepts, theories, and empirical research in behavioral and cognitive geography.

Perhaps many people are unaware that there is any effort within academic geography to understand human mind and behavior. Of course, many people probably don't understand academic geography very accurately; perhaps they don't understand behavioral science very well either (most behavioral scientists don't study rats or the neuroses you have from an overbearing mother). Here we define geography simply but richly as "the study of Earth as the home of humanity." That comprises both the natural and humanmade environments that make up our world, including their spatial, temporal, and thematic properties. Human behavioral sciences are "the study of the mind and behavior of humans." That includes what we think, feel, and do with our hands, legs, mouths, and the rest of our bodies, whether alone or in groups of individuals of any size. Of course, human mind and behavior occur - always - in the context of physical and sociocultural environments. We can thus define the study of behavioral and cognitive geography as the study of the psychology of space, place, and environment. This may sound obscure and esoteric, but it is anything but. Doing something in a particular place is a mundane and universal experience, and we all generally try to do what we desire to do, at the most appropriate time and in the best place possible, on many occasions every day. So behavioral and cognitive geography is very much concerned with everyday, widespread human phenomena. One may liken the common lack of awareness that such an area of scholarly inquiry exists to the adage that fish will be the last to discover water. 


\section{Handbook of behavioral and cognitive geography}

There are two primary reasons that geographers study questions of mind and behavior in space, place, and environment. The first is straightforward, maybe so much that it is often overlooked. Geography is concerned with problems of space, place, and environment. Thus, problems of mind and behavior concerning space, place, and environment are geographic problems in their own right. The second reason for behavioral and cognitive geography is more specific and historically conditioned. Geographers - particularly those who focus on human geography - have long taken as their central problem the description, prediction, and explanation of human activity in space and place. An important component of that effort has been the development and evaluation of social-scientific models of spatial behavior and interaction. Such behavior and interaction include travel, residential relocation, communication, land use, commodity exchange and distribution, and more. As Chapter 2 discusses, the behavioral approach originated in the 1960s as an attempt to address problems of spatial behavior and interaction by incorporating more detailed and realistic models of human psychology. This meant that human geography should be studied in the disaggregate instead of the aggregate, explaining spatial behavior at the level of individual people rather than just groups of people (families, neighborhoods, ethnic groups, states). This in turn led rather directly to the idea that an individual's observed spatial behavior is caused by that person's internal mental states and decisionmaking processes rather than "objective" reality itself. It also led to the recognition that individuals differ from each other, and theories that explain human behavior in space and place without recognizing and attempting to account for this variation are going to miss the mark. Behavioral geography (as it was first dubbed in Cox and Golledge 1969) thus provided an alternative to other approaches to explaining human geography that were widespread throughout the $19^{\text {th }}$ and $20^{\text {th }}$ centuries, including historical and cultural geography, environmental determinism, social physics, and classical economic rationality.

\subsection{THE DOMAIN AND APPROACH OF BEHAVIORAL AND COGNITIVE GEOGRAPHY}

Behavioral and cognitive geography attempts to describe and explain human activity and interactivity in space and place (Aitken et al. 1989). This includes where people carry out activities such as residential habitation, economic activities of production and consumption, socializing, leisure, and so on. It includes activities which are fundamentally interactive because they involve movement over the Earth's surface and contact between places. Examples of this include human travel and transportation, whether temporary like commuting or relatively permanent like residential relocation; the transportation of material or energy, including the commodity exchange of buying, selling, and trading; and communication, the movement of ideas and information.

As we have noted, the behavioral and cognitive approach typically favors mental explanations for observable behavior. But as a basic scientific endeavor, it also attempts to describe and explain mental phenomena such as thinking and feeling in their own right, without necessary regard for the degree to which they explain behavior. For example, practitioners of this approach want to describe and explain how people perceive and understand the environment, how they perceive and reason with symbolic representations of geographic information like maps and spatial language, how they conceptualize and 
respond emotionally to potential hazards and resources, how they come to love or hate places, and so on.

The behavioral and cognitive approach focuses on the individual person as a thinking, knowing, feeling agent. People are understood to be active information gatherers and processors, not passive recipients of stimuli, forces, or events. They evaluate alternative decisions against beliefs in order to make behavioral choices in space and place - primarily choices about where to go and how to get there. These beliefs are about spatial and non-spatial properties and relations of objects, events, and places. Spatial properties and relations include location, distance, direction, size, shape, sequence, connectivity, containment, and so on. Non-spatial properties and relations are temporal, including when something occurs, its duration, its rate and pattern of change, and so on. They are also thematic, including something's texture, its sweetness, its moisture content, its color, and so on. And they are hedonic, which are the positive or negative implications something has for people, i.e. its status as a potential resource or hazard. Of course, all these beliefs constitute critical determinants of spatial activity, and it is assumed that they normally function to do so adaptively. That is, they generally help us become oriented, move efficiently, make rewarding choices, avoid harm, communicate effectively, and so on. And these beliefs function more broadly than just serving a role in decision making - they organize and contextualize a person's ongoing experience of living in this world.

We can summarize four general characteristics of a behavioral and cognitive approach to geography. First, it is disaggregate rather than aggregate, focusing on the individual person as its main unit of analysis. Second, it maintains that behavioral activity is based on the world as perceived or conceived, rather than as it objectively exists. That is, internal mental states and processes mediate observed spatial behavior. Importantly, the subjective and objective worlds may deviate greatly from one another (see Chapter 6). Third, the interrelations of the individual and the environment are bi-directional - each affects the other. The environment is conceived broadly; it is both physical and sociocultural, and the physical environment is both natural and anthropogenic (built).

Finally, a fourth general characteristic of a behavioral and cognitive approach to geographic issues is its multidisciplinarity, even its interdisciplinarity (we take "multi-" to imply a collection of multiple disciplines and "inter-" as an interaction between disciplines that results in a new hybrid discipline). This is true in both concepts and methods. Disciplines and subdisciplines relevant to behavioral and cognitive geography include several areas of human geography, cartography, and geographic information science (GIScience); several areas of research psychology, including environmental, cognitive, perceptual, social, and developmental; other cognitive sciences such as computer science, philosophy, linguistics, and neuroscience; other social sciences such as sociology, economics, and anthropology; engineering disciplines; and design disciplines such as planning, architecture, landscape architecture, and interior design. The present Handbook fully embraces this multiple disciplinarity, including within its covers chapters by authors from several different disciplines and subdisciplines. Some of the chapters of the present Handbook critically discuss the historical and current role of the behavioral and cognitive approach within the discipline of geography, as well as the proper role of geography in the study of mind and activity in and concerning space, place, and environment. But my intent for this Handbook is not to be concerned with disciplinary appropriateness or influence but to provide a rich, comprehensive, and up-to-date overview of the wide assortment of 
research issues and activity in the domain of mind and behavior in and concerning space, place, and environment. It is problem organized much more than discipline organized. ${ }^{1}$

In fact, scholarly discussions of human mind have always taken place within the humanities and arts, not just scientific disciplines like most of those listed in the previous paragraph. Behavioral and cognitive geography has wrestled with its status as science or humanities, and followers of both styles of academic inquiry (under various names) currently pursue questions of human experience, mind, activity, place, and environment. Of course, the issue is not clear-cut and probably still is a matter of some contention. Clearly academic geography — particularly that focusing on humans - includes traditions that are relatively more like humanities or relatively more like sciences. With specific respect to behavioral and cognitive geography, much of the writing historically identified as environmental perception or place perception is more aptly recognized as humanitieslike if not philosophically humanistic (e.g. Buttimer and Seamon 1980; Relph 1976; Tuan 1974a); that identified as behavioral geography is more accurately recognized as scientific (e.g. Downs and Stea 1973; Golledge and Stimson 1987; Hägerstrand 1970). This Handbook takes no firm stance on the ultimate appropriateness or desirability of restricting behavioral and cognitive geography to one or the other tradition. It does accept that humanities and science are substantially different academic enterprises, including science that attempts to understand human nature and activity (i.e. social science, economic science, behavioral science, cognitive science). Both science and humanities strive to be rational exercises and tell us about human beings, and both have value as intellectual endeavors. But they generally involve different epistemologies, including the nature of what they consider to be empirical evidence, the systematicity with which they aspire to evaluate it, and their predilection for quantification, verbalization, or graphical expression. Prototypically, scientists hope for nomothetic, or at least widely applicable, truth; humanities scholars hope for idiographic truth, tied to specific times, places, and actors. The Handbook definitely features scientific work to a greater degree but does include work in the humanities tradition, particularly in Part VI on "Environmental Attitudes."

The behavioral and cognitive approach has attracted its share of criticism and prophecies of its imminent demise within the discipline of geography (see critiques and responses in, e.g. Bunting and Guelke 1979; Cloke et al. 1991; Gold 1992; Golledge 1981; Kitchin 2011; Tuan 1974b; see also Chapters 2 and 22 of this Handbook). Some criticism has involved misunderstanding, of course, such as the notion that behavioral geography implies psychological behaviorism, thoroughly debunked in this and other chapters of the Handbook. Other criticism is really a specific expression of the "culture war" within geography (played out in other social sciences as well) between scientific and non-scientific - or positivist and post-positivist - approaches to geography, particularly human geography (see Chapter 9). As discussed briefly above and in Chapter 2, behavioral geography was offered as a critique of some earlier approaches to human geography. Soon thereafter, a variety of approaches were offered in critique of the behavioral approach. Frameworks such as postmodernism, critical theory, feminism, and phenomenology argued that behavioral geography was mired in positivism and quantification, too restrictive to capture the rich diversity of human activity and experience. Its methods were variously claimed to be artificial; its explanations decontextualized from culture, politics, and society (especially in ignoring the key role of power relationships); inappropriately hung up on objectivity; and in the end, a product of white, patriarchal, bourgeois thought. 
A proper human geography, some argued, should focus on creating social justice, not just detached prediction and explanation.

Without taking on these critiques in detail here, and without implying a blanket dismissal of their points (they certainly have some merit), it is my intent in preparing this Handbook that it accepts the utility of a scientific approach to understanding human mind and behavior. But the Handbook is not premised on the idea that all important questions and all important aspects of questions can be answered scientifically. At the same time, the Handbook also rejects philosophical caricatures of science which claim that science must only follow the hypethetico-deductive method, that science only deals with directly observable phenomena, that science cannot study subjectivity, or that scientific progress is based on nothing but systematic analysis of quantitative data (i.e. "dustbowl" empiricism).

But there is a substantial caveat about the behavioral and cognitive approach to geography that I would like to address here. Befitting its status as widely held commonsense, most people - including most academic geographers - would probably endorse the manifest truth of the idea that people act because of what they believe. Also like commonsense reasoning in many cases, the apparent validity of the idea that people act because of what they believe probably derives mostly from informal personal experience and intuition, not from evaluation that is systematically rational and empirical (i.e. scientific). But even as an advocate and practitioner of behavioral and cognitive geography, as I am, I recognize that the idea that people's explicit beliefs determine their behavior is limited as an explanation of human behavior in space and place, some might even say surprisingly limited. For one, the idea is often applied in ways that overlook how much mental activity is implicit, beyond conscious access. For such mental activities, people will have no direct access to the mental states and processes behind their behavioral and emotional responses - they literally will not know why they did what they did or felt what they felt (and such implicit mental activity cannot, therefore, be studied simply by asking people about it). I also see merit in the claim that the behavioral and cognitive approach has often overlooked the role of non-mental causes of human behavior, such as the influences of social institutions, cultural norms, economic realities, technological opportunities and limitations, and so on (Ajzen 2001; Stern 2000).

These caveats aside, however, I am comfortable in asserting that the idea behind the behavioral and cognitive approach is certainly true to some non-trivial degree. In many situations, when people say they are going to do something because they believe it will help them achieve particular benefits or avoid particular costs, whether trivial or profound, they are sincere and correct. Thus, I find it incontestable that the ideas of the behavioral and cognitive approach are at least superficially plausible and that their scientific investigation is likely to be fruitful and worthwhile. This Handbook attempts to justify and expand on this position.

The terms "behavioral geography" and "cognitive geography" deserve some comment. The term behavioral geography, especially, can be a little misleading. For one, it is pretty accurate to say that all human geographers study human behavior or the effects thereof. Another potential confusion is that behavioral could misleadingly suggest the philosophical position of "behaviorism," as we mentioned above. Without going into detail, little could be further from the truth than to assign the anti-mentalism and passive responsiveness of behaviorism to the approach of behavioral geography. We explicitly 
avoid these confusions about behavioral by including the term cognitive in the title of this Handbook, signaling our interest in mind and mental explanations for behavior. Nonetheless, it must be recognized that all behavioral geography is not explicitly mental; several chapters in this Handbook make that clear. The term cognitive is about knowing and knowledge (believing and beliefs), but we definitely include emotional influences on human-environment relations in this Handbook. To a large extent, I believe the term "psychological geography" would most aptly convey what this field is about. Or a personal favorite of mine: psychogeography! Unfortunately, this term was appropriated several decades ago by a group of politically left-leaning artists and philosophers to refer to a humanistic approach that relates emotion and experience to "everyday places of being and existence" (exploring the role of place in phenomenology). It is thus doubtful that we could successfully claim the term psychogeography for our own, even if we are actually geographers and psychologists, and the average psychogeographer is neither. True, we do see the concerns of behavioral and cognitive geography as at least partly overlapping with those of the humanistic psychogeographers, but I doubt that most of the work covered in the present Handbook would qualify any of us for membership in organizations like the London or New York Psychogeographical Associations.

\subsection{BASIC CONCEPTS OF MIND AND BEHAVIOR}

Given that behavioral and cognitive geography is the study of mind and behavior concerning space, place, and environment, it is informative to define some basic concepts of mind and behavior. Sensation is the first response of the nervous system to stimulation from the world. Receptor cells transduce patterns of energy in the environment into patterns of energy in the nervous system. The energy in the environment is electromagnetic, chemical, pressural and vibrational, gravitational, and thermal. In the nervous system, it is electrical and chemical. The patterns in both are spatiotemporal patterns, and the presence of pattern is the basis for the information or semantic content the energy can represent. The concept of sensory modalities captures the fact that different types of sensations are experienced qualitatively differently, occur in response to different types of environmental energy, result from the stimulation of different types of receptors, and reflect or encode different properties of the world. For example, seeing a pattern of light is experienced qualitatively differently from hearing a pattern of sound, electromagnetic energy is different from atmospheric vibration, rods in the retina are different from hair cells in the cochlea, and shape is different from pitch. Since at least Aristotle's writings, people have widely held that humans have five sensory modalities. This is rather misleading, and while it is difficult to say conclusively how many modalities we have, it is apparent that it is more than five (even without allowing for ESP!). These include vision, hearing, smelling, and tasting. The customary fifth sense of touch in fact combines the separate senses of pressure, texture, temperature, and (somewhat ambiguously) pain. In addition, kinesthesis is the sensing of

limb position and movement, and vestibular sensing responds to gravity and linear/angular acceleration of the body. These latter two proprioceptive senses provide people with important information about their body position and movement, which in turn informs them about their location and movement, and about the layout of their surrounding environment (e.g. about the shape of the route they have just followed along city streets). 
In contrast to sensation, which is the low-level response of a stimulated nervous system to patterned energy in the environment, perception is the high-level acquisition of beliefs about oneself and the world derived from some combination of sensation and prior belief/knowledge. ${ }^{2}$ That is, perception leads to ideas about meaningful objects, events, and properties that are being sensed via one or more modality. Perception is part of the larger concept of cognition, which refers to structures and processes of knowing and knowledge (believing/beliefs). In addition to perception, cognition includes the specific structures and processes of thinking, learning, memory, attention, imagery, language, conceptualization, reasoning, and problem-solving. Some cognition is conscious or explicit, subject to awareness. But it is critically important to recognize that much of it is implicit, outside of awareness. As we discussed above in the section on critiques of behavioral and cognitive geography, researchers cannot directly study such unconscious mental states and processes simply by asking people about theirs - by definition, they do not have conscious access to them. Nonetheless, implicit cognition certainly is a proper subject of study for behavioral and cognitive geographers.

Human experience and decision-making are also emotional or affective. Colloquially called feelings (as are sensations), emotions are mental states that color experience and motivate behavior, and include a component of positive or negative evaluation or hedonic tone, and a component of activity or arousal. Examples include happiness, satisfaction, joy, sadness, boredom, anger, and fear. Emotions are influenced by what one perceives and what one thinks about, remembers, or imagines. In turn, emotions influence what one perceives, thinks about, remembers, or imagines. An especially important concept for behavioral and cognitive geography is that of attitude, which is a belief coupled with an affective stance, sometimes linked to an intention to act. An example of an environmental attitude would be "I think that burning coal causes greenhouse gas buildup, a state of affairs that worries me."

Finally, behavior is potentially observable, goal-directed body movement, sometimes called motor behavior, action, or activity. The movement can be the entire body or any part thereof. Examples include locomotion, gesturing, manipulation of objects, and speaking or writing. Unlike some opinions about the fabled tree in the forest, unwitnessed movement is still behavior as long as it could potentially be observed. But this movement must be goal-directed, whether the goal is putting your body in a location, moving flour from the cupboard to the bowl, or communicating a belief to a friend. Falling after slipping on a peel is not behavior; catching your fall with your hand is. Like emotion, behavior is influenced by perception and cognition and, in turn, influences perception and cognition. The latter influence may be less obvious, but consider how we turn our heads so we can see or hear something better.

Finally, we consider the meaning and relation of mind and brain. Mind refers to the collection of conscious and unconscious states and processes in sentient beings that are constituted in activities such as perceiving, thinking, feeling, willing, remembering, and imagining. Mind is semiotic in that it consists of representations or information that express meaning. The brain, in contrast, is a physical organ within the skull, connected to a nervous system that runs throughout the body. A venerable philosophical question is the "mind-body question": what is the nature of mind (experience, awareness, soul, spirit), the nature of body (brain, nervous system, body, physical world), and their relationship? Of course, many answers to this question have been offered over the centuries, from 
idealism to materialism to interactionism of many varieties. There is no serious doubt that the nervous system (led by the brain) is the main anatomical basis for mind, or that mind is one of the main purposes of the nervous system. But the evident role of the brain does not force us to accept a reductionist philosophy that places the causal precedent for mind and behavior on the brain alone. Many behavioral and cognitive scientists (including me) believe the mind emerges from a brain and nervous system in a physical body, which in turn is in a physical and social world. A complex nervous system is required for mind, but mind is not reducible just to brain. This view sees the science-fiction scenario of downloading a mind or sentient brain "into a jar" as unlikely or at least a perversion of normal mind. Most of this Handbook focuses on mind and behavior rather than brain, although there have been great advances in the last couple of decades in understanding the relation of mind and behavior to brain, from a discipline known as cognitive neuroscience. As Chapter 9 reviews extensively, and several other chapters discuss more briefly, geography is no exception.

\subsection{BOOK OVERVIEW}

This Handbook consists of 22 chapters covering a broad and diverse set of topics within the field of behavioral and cognitive geography. The book attempts to be comprehensive. Indeed, most scholars trained strictly in geography will be surprised at its great breadth, breadth deriving largely from the great multi- and interdisciplinary spirit in which the book was created. Scholars in other disciplines will likely find its breadth even more surprising, insofar as they may not be aware of the breadth of modern research geography.

That said, some topics could be covered more extensively in the Handbook. As I summarize below, the book includes chapters on spatial decision making and human travel behavior. But it could more extensively and specifically discuss work on economic decision making, including both by firms and consumers. Retail decision making - where to buy something-has long been a favorite topic for behavioral geographers, but is only mentioned in passing Chapter 3 , which has wider goals. Temporary travel, such as commuting, is rather thoroughly covered in the Handbook, but more could be said about behavioral models of migration and residential search, more permanent forms of travel. Behavioral and cognitive aspects of leisure and recreation are relevant to tourism studies but are not much covered here. The Handbook includes a chapter on spatial behavior and cognition by those with visual impairment, but behavioral and cognitive geography certainly has things to say about persons with a wider set of disability conditions. There is a chapter on childhood education that grapples head-on with the subject of children's spatial thinking, but more could be said about thematic and temporal aspects of children's geographical behavior and cognition; indeed, the Handbook in general could focus more on thematic and temporal behavior and cognition. And it has very little to say about development over the entire lifespan, including the geographic behavior and cognition of older adults. Although hazardous and aesthetic implications of environments are covered well in this Handbook, the focus is almost entirely on natural environments, not built environments such as cities.

With those cases of patchiness in mind (and one must assume others), the Handbook clearly provides an impressively broad and diverse coverage of topics relevant to 
behavioral and cognitive geography. To help present the 22 chapters more coherently, they are organized into Parts I-VIII. As one would expect, Part I is provides an "Introduction and Background." Of course, it is introductory and historical in its perspective, starting with the Chapter 1 you are now reading, "Introduction and overview." Chapter 2, by Juval Portugali, discusses "History and theoretical perspectives of behavioral and cognitive geography." He places the emergence of behavioral geography and then cognitive geography squarely within the traditions of $19^{\text {th }}$ and $20^{\text {th }}$ century academic geography, particularly human geography. This includes the "theory wars" that continue within human geography, primarily a debate between so-called "positivist" and "post-positivist" approaches (scientific vs critical, quantitative vs qualitative, etc.). Later, the chapter engages geographic information systems and science. However, Portugali also situates the emergence of behavioral and cognitive geography in the context of a "cognitive revolution" in psychology and then the cognitive sciences (even in planning and architecture). This evolves from classic cognitivism to embodied cognition, connectionism, and complexity theory. A detailed example of the latter is Portugali's own extensive and interesting work on the specific theoretical framework of "synergetic inter-representation networks." In his review of the past, Portugali naturally points to some possible futures for the behavioral and cognitive approach.

Part II is "Spatial Behavior and Decision Making." It presents work on spatial behavior and decision making, core research domains from the earliest days of behavioral geography. As we reviewed above, human geographers have long considered their task to be understanding human spatial behaviors and interaction, whether economic activities, leisure activities, migration, commuting, or communication. Such an understanding need not invoke mental explanations, and indeed, much of the work summarized in this part focuses on describing and explaining human activity without necessarily accounting for it by explicit reference to the mind. However, all of this work shares the tendency to understand human activity at the disaggregate level of the individual person. It also attempts to improve models of spatial behavior by applying more complex and realistic ideas about human psychology than models based on the assumption of economic rationality or the simple ideas of social physics. Chapters 3-5 in this part are "Behavioral decision theory in spatial decision-making models" by Piotr Jankowski; "Travel behavior models" by Konstadinos G. Goulias; and "Time geography” by Harvey J. Miller.

Part III is about "Environmental Spatial Cognition," the nature of people's thinking and memory centrally involving spatial properties of environmental spaces, spaces like parks, neighborhoods, campuses, towns, or buildings. The spatial layout of environments in this sense can eventually be apprehended by direct experience - at least by some people - but is large enough so that people have to locomote around (walk, bike, etc.) over considerable time (at least minutes) to complete that direct experience. Thus, information gleaned during locomotion must be mentally combined to construct something approaching a global understanding of the environment - a cognitive map. Alternatively, people can shortcut this process by using cartographic maps or linguistic descriptions, and some "environments" are so large - large cities, provinces, countries - that they can hardly be apprehended without such indirect symbolic input. Relevant spatial properties include both metric properties like distance, direction, and size, and non-metric properties like sequence, overlap, and connection. Research in this area is very concerned with the nature of spatial knowledge structures and processes of reasoning, including the acquisition 


\section{Handbook of behavioral and cognitive geography}

and development of knowledge, and its use in tasks such as navigation - place-directed locomotion. Given advances in neuroscience technologies for studying spatial cognition, much of this research now focuses not only on mind but on brain. In this part, Chapters 6-9 are "Environmental knowledge: cognitive flexibility in structures and processes" by Holly A. Taylor, Aaron L. Gardony, and Tad T. Brunyé, "Learning the environment: the acquisition of cognitive maps" by Toru Ishikawa, "Wayfinding and orientation: cognitive aspects of human navigation" by Stephen C. Hirtle, and "Cognitive neuroscience of spatial and geographic thinking" by Victor R. Schinazi and Tyler Thrash.

Part IV on "Cognitive Aspects of Geographic Information" examines work in GIScience that attempts to understand earth-referenced information and the geographic information systems (GIS) for storing, processing, analyzing, and presenting this information, from the perspective of human cognition. Geographic information is created by humans for use by humans; understanding human cognition should thus be important for understanding geographic information and its use by humans, including the improvement of GIS. Improving GIS means making them easier and more pleasurable to use, more powerful, more compatible with human thinking, more profitable, more equitably available, and so on. These ideas were recognized almost from the origins of the scientific study of geographic information (Goodchild 1992; McMaster and Usery 2005) and much earlier specifically in the domain of cartography - geographic information display. Geographic information comes from direct experience in the world - such as fieldworkbut often indirectly from symbolic sources such as cartographic maps, photographs, satellite data, and natural language. Undoubtedly, the contributions of these different sources of information have substantial implications for geographic cognition (Montello and Freundschuh 1995). The chapters in this part, Chapters 10-12, are "Cognitive perspectives on cartography and other geographic information visualizations" by myself, Sara Irina Fabrikant, and Clare Davies, "Cognition and geographic information technologies" by Martin Raubal, and "Natural language and geography: the meaning and use of spatial concepts in geographical contexts" by Thora Tenbrink.

"Individual and Group Differences in Geographic Behavior and Cognition" is Part V. As reviewed above and in other chapters of this Handbook, taking human variation seriously - both theoretically and empirically - is one of the defining characteristics of the behavioral approach within geography. To most behavioral geographers, an analysis of variation starts at the level of the individual person - no two individuals are identical, even "identical" twins. But we might gain additional understanding of variation by aggregating individuals into groups based on sex, gender, age, education, expertise, ethnicity, language, culture, socioeconomic status, body size, and so on. In performing cognitive tasks, people can be distinguished according to abilities, strategies, or reasoning styles. Of course, documenting patterns of similarities and differences is logically a necessary precursor to explaining them; explaining them is a profoundly challenging endeavor, in large part because one can rarely if ever experimentally manipulate individual or group differences with humans. While the behavioral approach is notable for its recognition of human differences, however, it still mostly attempts to do so scientifically - while attempting to identify general explanations for variation as much as possible. Critiques of the behavioral approach often seem to object to it for this adherence to general explanation, implying that it is almost autocratic (to state it dramatically) in its insistence that people can be understood generically. Chapters $13-15$ in this part are "Individual differences 
in large-scale spatial abilities and strategies" by Mary Hegarty, Heather Burte, and Alexander P. Boone, "Sex and gender in geographic behavior and cognition" by Carol A. Lawton, and "Navigating without vision: principles of blind spatial cognition" by Nicholas A. Giudice.

Part VI on "Environmental Attitudes" most explicitly explores mind phenomenologically, as consciously experienced reality. Because of the prominence of emotionality in moment-to-moment experience, this part also considers the role of emotions or affect in geographic behavior and cognition more than other parts (Chapter 10 does consider emotions in cartographic communication). Emotional states clearly play a very large role in explaining behavior, and as major constituents of experience, are worthy of understanding in their own right. They greatly influence decisions people make about whether and where to move, shop, vacation, work, and so on. They also greatly influence health, job performance, productivity, and general life satisfaction. As discussed above, attitudes are beliefs coupled with emotional responses to the belief. The relationship of attitudes to behavior has been a core question in disciplines like social psychology and political science for several decades, but the relationship is surprisingly complex and subtle (Albarracin et al. 2014). Contrary to the common lay idea (and early scientific theory) that attitudes strongly and directly cause behaviors - part of the intuitive reasoning about why people do what they do that we introduced above - researchers have evaluated increasingly complex models to explain behavior that incorporate causes such as values, motivations, norms, and efficacy beliefs; contextual factors such as social, cultural, economic, institutional, legal, political, technological, and physical; personal capabilities such as knowledge, skills, available time, and available money; and habits and routines (Stern 2000). Chapters 16-18 in this part are "Place" by Pragya Agarwal; "Environmental aesthetics" by Sara Hadavi and William C. Sullivan; and "Environmental risks and hazards from a cognitive-behavioral perspective" by Patricia Gober.

Part VII addresses "Further Disciplinary Applications of Cognitive-behavioral Geography," research relevant to behavioral and cognitive geography that explicitly incorporates the work of disciplines besides geography and research psychology. This part is naturally something of a grab bag, but an approach such as behavioral and cognitive geography that is so broad and explicitly problem- rather than discipline-oriented is always rightly going to include within its province such a collection. Chapters 19-21 in this part are "Architectural cognition and behavior" by Ruth Conroy Dalton, Jakub Krukar, and Christoph Hölscher, "Artificial intelligence and behavioral geography" by Paul M. Torrens, and "Early geographic education: cognitive considerations" by David Uttal.

Finally, the single chapter of Part VIII provides a "Coda" for this Handbook. Roger Downs titles his Chapter 22 "The future of behavioral and cognitive geography: a coda." As Part I is introductory and historical, Part VIII is conclusional and future-directed. But just as Portugali hints at the future of behavioral and cognitive geography in his review of the past, Downs uses the $20^{\text {th }}$ century history of academic geography to contextualize his thoughts about its $21^{\text {st }}$ century future. That $20^{\text {th }}$-century past was apparently an intellectually exciting but rather fraught time for geography. With the behavioral and, then, cognitive approaches, some geographers embraced first the idea of the individual as persona geographicus, and then the idea that this person actually has a mind, a mind sometimes used to think about what is on the Earth, where it is, how to get there, and whether it is worth visiting or avoiding. Downs muses amusingly about the steps and missteps 


\section{Handbook of behavioral and cognitive geography}

of behavioral and cognitive geography, organized around the Rumsfeldian notions of "known knowns," "known unknowns," and "unknown unknowns." He characterizes the previous chapters of this Handbook as covering in detail the known knowns and known unknowns of behavioral and cognitive geography. He takes as the balance of his task a series of speculations about the unknown unknowns. These include speculations on limits to the exaggerated application of the cognitive-map concept, the well-known cartographic metaphor for human geographic understanding. Downs expresses excitement for recent developments in neuroscience, especially considering that some of the most celebrated such work has been on spatial learning, wayfinding, and orientation in the environment. But his excitement is tempered by recognition of the dangers of excessive reductionism and overly simplistic causality that adopting neuroscientific explanation could engender. In the end, Downs's chapter provides a fitting coda for the entire Handbook by considering the implications of digital geospatial technologies, particularly GPS-enabled technologies, for human behavior and mind in space, place, and environment. One hopes their "Panopticonic" reach ultimately proves more beneficent than maleficent.

\section{NOTES}

1. This is squarely in the spirit of Donald T. Campbell's (1969) famous "fish-scale model of omniscience," which Professor Stephen West introduced to me in graduate school. It continues to impact my thinking to this day.

2. This defines perception as a psychologist would by restricting it to acquiring beliefs about the meaning of one's concurrent sensory inputs - what is out there that I am seeing, hearing, etc. Geographers usually define it more as lay people would, to refer generically to beliefs or attitudes whether based on concurrent sensing or not. To a geographer, one can perceive the risks and hazards of coal mining; to a psychologist, one mostly cannot (a collapsed mine notwithstanding).

\section{REFERENCES}

Aitken, S.C., S.L. Cutter, K.E. Foote and J.L. Sell (1989), Environmental perception and behavioral geography, in C.J. Wilmott and G. Gaile (eds), Geography in America, Columbus, OH, USA: Merrill, pp. 218-238.

Ajzen, I. (2001), Nature and operation of attitudes, Annual Review of Psychology, 52 (1), $27-58$.

Albarracin, D., B.T. Johnson and M.P. Zanna (eds) (2014), The Handbook of Attitudes, New York: Psychology Press.

Bunting, T.E. and L. Guelke (1979), Behavioral and perception geography: A critical appraisal, Annals of the Association of American Geographers, 69 (3), 448-462.

Buttimer, A. and D. Seamon (1980), The Human Experience of Space and Place, New York: St Martin's Press.

Campbell, D.T. (1969), Ethnocentrism of disciplines and the fish-scale model of omniscience, in M. Sherif and C.W. Sherif (eds), Interdisciplinary Relationships in the Social Sciences, Chicago, IL: Aldine, pp. 328-348.

Cloke, P.J., C. Philo and D. Sadler (1991), Approaching Human Geography: An Introduction to Contemporary Theoretical Debates, New York: Guilford Press.

Cox, K.R. and R.G. Golledge (eds) (1969), Behavioral Problems in Geography: A Symposium, Evanston, IL: Northwestern University.

Downs, R.M. and D. Stea (eds) (1973), Image and Environment, Chicago, IL: Aldine.

Egenhofer, M.J. and D.M. Mark (1995), Naive geography, in A.U. Frank and W. Kuhn (eds), Spatial Information Theory: A Theoretical Basis for GIS, Berlin: Springer, pp. 1-15.

Gold, J.R. (1992), Image and environment: The decline of cognitive-behaviouralism in human geography and grounds for regeneration, Geoforum, 23 (2), 239-247.

Golledge, R.G. (1981), Misconceptions, misinterpretations, and misrepresentations of behavioral approaches in human geography, Environment and Planning A, 13, 1325-1344.

Golledge, R.G. and R.J. Stimson (1987), Analytical Behavioural Geography, London: Croom Helm. 
Goodchild, M.F. (1992), Geographical information science, International Journal of Geographical Information Systems, 6 (1), 31-45.

Hägerstrand, T. (1970), What about people in regional science?, Papers of the Regional Science Association, XXIV, 7-21.

Hobbs, J.R. and R.C. Moore (eds) (1985), Formal Theories of the Commonsense World, Norwood, NJ: Ablex.

Kitchin, R. (2011), Reginald Golledge, in P. Hubbard and R. Kitchin (eds), Key Thinkers on Space and Place, 2nd edition, Los Angeles, CA: Sage, pp. 188-191.

Malle, B.F. (2004), How the Mind Explains Behavior: Folk Explanations, Meaning, and Social Interaction, Cambridge, MA: MIT Press.

McMaster, R.B. and E.L. Usery (eds) (2005), A Research Agenda for Geographic Information Science, Boca Raton, FL: CRC Press.

Montello, D.R. and S.M. Freundschuh (1995), Sources of spatial knowledge and their implications for GIS: An introduction, Geographical Systems, 2 (3), 169-176.

Relph, E. (1976), Place and Placelessness, London: Pion.

Ross, L. (1977), The intuitive psychologist and his shortcomings: Distortions in the attribution process, in L. Berkowitz (ed.), Advances in Experimental Social Psychology 10, New York: Academic Press, pp. 173-220.

Stern, P.C. (2000), Toward a coherent theory of environmentally significant behavior, Journal of Social Issues, 56, 407-424.

Tuan, Y.-F. (1974a), Topophilia: A Study of Environmental Perception, Attitudes, and Values, Englewood Cliffs, NJ: Prentice-Hall.

Tuan, Y.-F. (1974b), Review of "Mental Maps" by Gould and White, Annals of the Association of American Geographers, 64, 589-591. 